\title{
Correction to: The effect of CA1 dopaminergic system on amnesia induced by harmane in mice
}

\author{
Mohammad Nasehi ${ }^{1}$ - Sedigheh Hasanvand ${ }^{2}$ - Fatemeh Khakpai ${ }^{1} \cdot$ Mohammad-Reza Zarrindast ${ }^{3,4,5}$
}

Published online: 28 June 2018

(c) Belgian Neurological Society 2018

\section{Correction to: Acta Neurologica Belgica}

https://doi.org/10.1007/s13760-018-0926-8

Unfortunately, the second author name was incorrectly published in the original article. The complete correct name should read as follows:

Sedigheh Hasanvand

The original article has been updated.

The original article can be found online at https://doi.org/10.1007/ s13760-018-0926-8.

Mohammad-Reza Zarrindast

zarinmr@ams.ac.ir

1 Cognitive and Neuroscience Research Center (CNRC),

Tehran Medical Sciences Branch, Islamic Azad University,

Tehran, Iran

2 Department of Biology, Faculty of Basic Sciences, Northern

Branch, Islamic Azad University, Tehran, Iran

3 Department of Pharmacology, School of Medicine, Tehran University of Medical Sciences, Tehran 13145-784, Iran

4 Iranian National Center for Addiction Studies, Tehran University of Medical Sciences, Tehran, Iran

5 Endocrinology and Metabolism Research Center,

Endocrinology and Metabolism Clinical Sciences Institute,

Tehran University of Medical Sciences, Tehran, Iran 